Document downloaded from:

http://hdl.handle.net/10251/145994

This paper must be cited as:

Serrano, J.; Piqueras, P.; Navarro, R.; Tarí, D.; Meano, CM. (15-0). Development and verification of an in-flow water condensation model for 3D-CFD simulations of humid air streams mixing. Computers \& Fluids. 167:158-165.

https://doi.org/10.1016/j.compfluid.2018.02.032

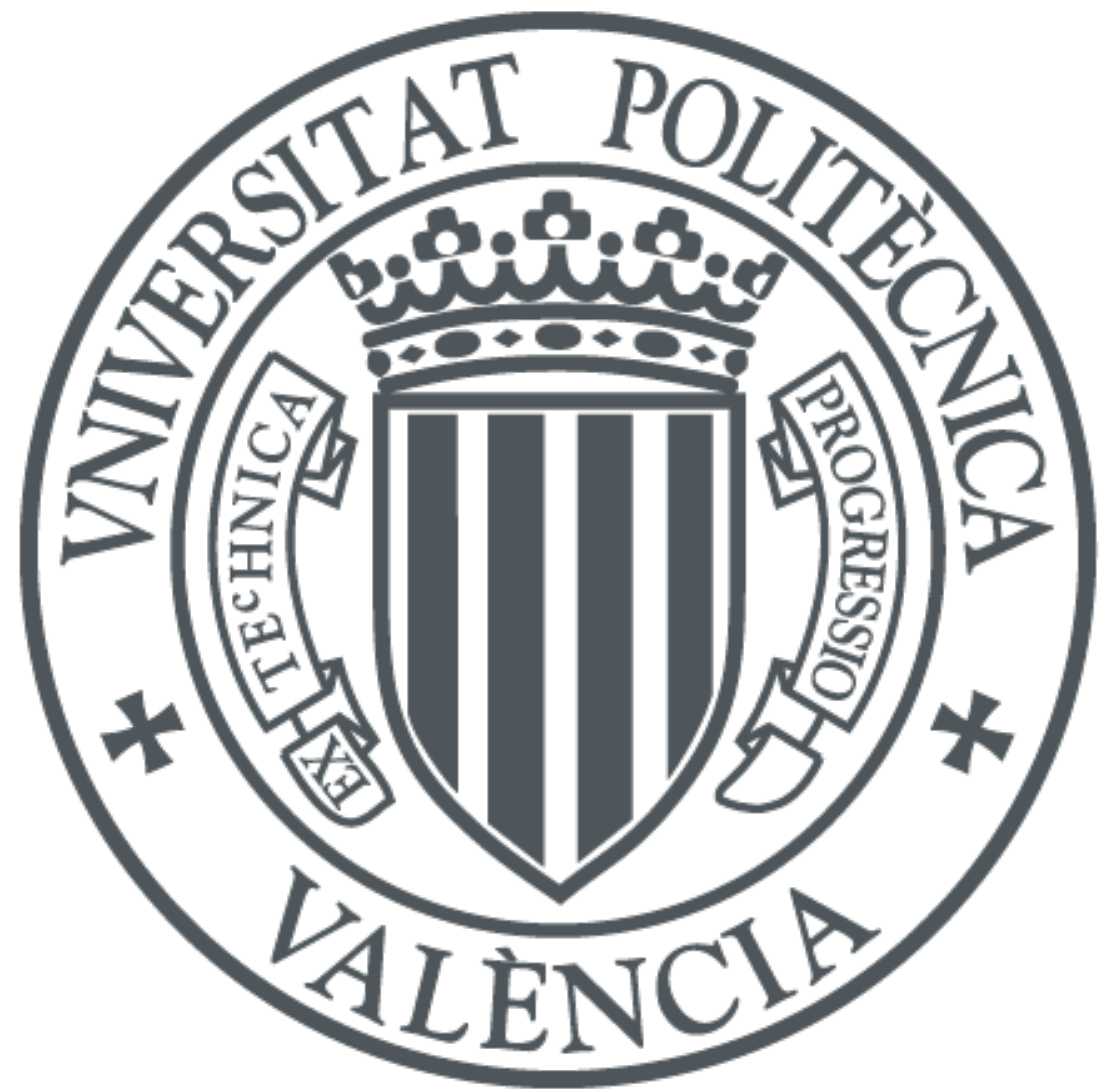

The final publication is available at

https://doi.org/10.1016/j.compfluid.2018.02.032

Copyright Elsevier

Additional Information 


\section{NOTICE:}

this is the author's version of a work that was accepted for publication in Computers \& Fluids. Changes resulting from the publishing process, such as peer review, editing, corrections, structural formatting, and other quality control mechanisms may not be reflected in this document. Changes may have been made to this work since it was submitted for publication. A definitive version was subsequently published as [1]:

\section{References}

[1] J. Serrano, P. Piqueras, R. Navarro, D. Tarí, C. Meano, Development and verification of an in-flow wa ter condensation mo del for 3D-CFD simulations of humid air streams mixing, Computers \& Fluids 167 (2018) 158 165. doi:10.1016/j.compfluid.2018.02.032 


\title{
Development and verification of an in-flow water condensation model for 3D-CFD simulations of humid air streams mixing
}

\author{
J.R. Serrano ${ }^{a}$, P. Piqueras ${ }^{\mathrm{a}}$, R. Navarro ${ }^{\mathrm{a}}$, D. Taría ${ }^{\mathrm{a}}$, C.M. Meano ${ }^{\mathrm{b}}$ \\ ${ }^{a}$ CMT - Motores Térmicos, Universitat Politècnica de València \\ Camino de Vera, 46022 Valencia \\ ${ }^{b}$ GM Global Propulsion Systems-Torino Srl Corso Castelfidardo 36 - 10129 Torino (I)
}

\begin{abstract}
Bulk flow condensation caused by the mixing of air streams at different temperatures and humidities is a thermodynamic process that requires strong assumptions to be calculated with low computational effort. The applicability of a model that correctly predicts this phenomenon has grown recently due in part to the deployment of the Long Route Exhaust Gas Recirculation emission reduction technique in combustion engines and the damage to the turbocharger caused by the condensation produced when the intake air is mixed with the combustion gases. This work is addressed to expose a condensation model that is implemented in a commercial 3D-CFD code and is then verified, checking whether the implemented physical equations are behaving as intended. Finally, a practical application is made, showing the potential of model to predict water condensation in a LR-EGR T-joint.

Keywords: Turbocharger, Computational Fluid Dynamics, Long Route EGR, Compressor damage
\end{abstract}

\section{Introduction}

Due to the constant increase of emission regulations restrictions and the competitiveness in automotive engines, techniques that seek better efficiency

Email addresses: jrserran@mot.upv.es (J.R. Serrano), pedpicab@mot.upv.es (P. Piqueras), ronagar 1 @mot.upv.es (R. Navarro), datade@mot.upv.es (D. Tarí), cesare.meano@gm.com (C.M. Meano) 
combined with low emissions are being developed constantly. This non trivial combination of goals also requires improving or keeping the mechanical power.

Emissions reduction technologies used nowadays are either in-cylinder control or aftertreatment $(\mathrm{A} / \mathrm{T})$ control [1, 2]. In-cylinder control systems reduce the generation of emissions within the source, during the combustion process. For instance, controlling the injection scheme [3], the maximum in-cylinder pressure, with thermal management [4] or using recirculating exhaust gases (EGR). On the other side, A/T systems reduce pollutant emissions along the exhaust line [5], such as diesel particulate filters (DPFs), selective catalytic reduction (SCR) or diesel oxidation catalysts (DOC) 6] . This work is focused on one of these systems, specifically on the exhaust gas recirculation (EGR). This consists in reintroducing part of the exhaust gases resulting from the combustion process back again in the cylinders mixed with fresh air, which causes a decrease in the maximum temperature achieved during the combustion process so that the Nitrogen oxides ( $\mathrm{NOx}$ ) formation is reduced while the mean pressure in the cylinders is kept almost the same. EGR most common application is CI engines, nevertheless it is beneficial in turbocharged SI engines too [7, 8].

As turbochargers are indispensable in diesel engines, two possible paths of recirculation are available. Nowadays, the most common configuration consists in connecting both outlet and inlet manifolds, resulting in the socalled high-pressure or short route EGR (SR-EGR). Using this connection, a cooler and a valve to control the mass flow rate are usually employed. This system has been very popular during the last decades due to its simplicity. However, as it will be explained below, it introduces some drawbacks which are partially avoided by using the long route EGR (LR-EGR), which consists in extracting part of the low-pressure gases downstream the turbine and DPF and reintroducing them before the compressor.

The main practical difference between these two EGR configurations resides in the mass flow going through the turbine and the compressor. As the SR-EGR valve opens, the flow passing the turbocharger is reduced, shifting the working point towards generally lower efficiency values and reducing the compressor surge margin, hence requiring a selection of turbomachinery that withstands good performance over a wide range of operating conditions. In addition, lowering the turbine mass flow implies reducing its power, worsening its transient response as stated by Desantes et al. [9]. Conversely, with LR-EGR the turbine mass flow rate is not directly affected by the valve 
opening. From the point of view of air charge, the SR-EGR loop leads to an increase in the intake manifold temperature, which has a negative effect on BSFC (see Ladommatos et al. [10] and Desantes et al. [9]). Finally, a relevant aspect of the engine performance is the cylinder to cylinder EGR distribution. SR-EGR system may not be able to uniformly distribute EGR gas between the cylinders because the EGR outlet duct discharges over the inlet manifold, and the flow may not have enough time to be mixed with fresh air. This phenomenon is responsible for possible dis-uniformities of charge among cylinders [11]. On the opposite hand, LR-EGR mixes both flows far upstream the cylinders, letting a perfect distribution of the EGR gas between them.

Hence, the LR-EGR may look like a better solution although it is not without drawbacks [9, 12]. Firstly, it presents a higher design complexity since inlet and outlet connections are relatively far from each other, meaning longer ducts within the underhood. In addition, the volume of the whole ducting implies a transient buffer of exhaust gas mass flow, which may decrease EGR rate responsiveness. The addition of the EGR discharge upstream the compressor produces a geometry modification that may impact on the compressor performance, as studied previously by some authors [13, 14]. Finally, due to the high water content of the EGR flow, condensation may arise provided that the necessary conditions are met. This may be a problem for the LR-EGR, since water droplets may damage the compressor wheel. For the SR-EGR, since the exhaust gases are reintroduced downstream the compressor, condensation is less critical. In fact it may even be a feasible technique for on-board regeneration of the cooler efficiency [15, 16].

Condensation when using LR-EGR may be produced in the EGR cooler as well. Despite the lower acidity due to suspended contaminants than in SR EGR [17, 18], condensation may still cause damage to the compressor wheel. LR-EGR condensation may also be produced within the flow when EGR stream is mixed with cold ambient fresh air. A combination of both ambient and engine/EGR operating point conditions may lead the mixing process to reach saturated conditions and the water to condensate. For example, ambient temperatures below +5 to $+10{ }^{\circ} \mathrm{C}$ are susceptible to condensate EGR within the bulk of the mixing region for moderate EGR rates.

If condensation occurs, water droplets are driven towards the compressor wheel which is normally rotating at very high speed, implying elevated relative momentum and impact damage [19]. Dramatic consequences are observed at the leading edges of the compressor wheel if droplets impact the 
blades for long enough, as noticed by Serrano et al. [20]. Surface coating is normally applied to the wheel, partially protecting against this erosion, partially protecting against this erosion, nevertheless it is not infallible, as observed by Koka et al. [21]. Once the water penetrates the compressor inducer, due to its inertia, it may not follow the air streamlines but get attached to the wheel walls, forming rivers and leaving depositions [20]. The load of the compressor wheel may also change, according to Surendran et al. 22 .

The complexity of the condensation within the flow has to be remarked. Wall condensation in the interior of tubes has been deeply studied by many authors [23, 24], and wall condensation in free streams by others [25, 26, 27]. However, bulk flow condensation has not been researched extensively because there are less applications in which this process is important and in addition, a combination of both 3D fluid dynamic and psychrometric models are needed, since the complex turbulent flow structures upstream the compressor [14] and the mixing process control condensation rate [28]. Condensation will be produced at constant pressure and as a consequence of the mixing of two different flows at different psychrometric conditions.

It is worth noting that a different cause that also produces condensation in the bulk flow has been studied by Moses et al. [29] and later Grübel et al. [30, where the water appears due to the decrease of temperature caused by the acceleration of the flow in a de Laval nozzle. Due to the high velocities found in these sort of nozzles, small errors predicting the appearance of condensation imply greater errors in its location, therefore complex models that accurately predict the appearance and growth of water droplets within the fluid are required. The model developed in this work would not be suitable for solving this type of condensation.

The CFD code used for this work is CD-adapco STAR-CCM+ ${ }^{\circledR}$ [31] which allows the creation of user field functions, enabling the implementation of a custom condensation model, as will be explained afterwards.

This paper is organized as follows. Next section starts with a summary of the background of the problem, introducing the available models and a definition of the verification process that is going to be performed. Then, a simple geometry will be defined followed by the development of the condensation model to be implemented in the 3D-CFD code. Afterwards, a discussion of the results obtained with the CFD simulation and a comparison with another condensation model at different operating conditions will be shown. A practical example of the condensation model will follow and finally, some 
concluding remarks will be provided.

\section{Background and model validation strategy}

With respect to 3D-CFD calculation model, a first exploration of diverse possibilities available in the STAR-CCM+ ${ }^{\circledR}$ 31 code leads this study to the so-called "Defogging model", which claims to simulate defogging (evaporation) inside a cabin windshield or surface [32]. In spite of condensation not being the main scope application of this model, there is an important aspect of the Defogging model that could be used. A property which may be enabled consists in a super saturation limitation, that controls the specific humidity not to exceed saturation conditions by condensing vapor into water. However, numerical experiments show that condensation is produced isothermally in Defogging model as shown in Fig. 11. This is not suitable as condensation should be an isenthalpic process [33, 34]. The isothermal process is the result of removing the vapor content of the gas without releasing the latent heat of the condensation, what implies a greater amount of condensates at the end of the process. Hence, this model cannot be used for this work since the super saturation limitation is intended only to bound the problem but not to be used as an independent application itself.

Having discarded the Defogging model, another solution is proposed, considering that condensation acts as a sink of vapor mass and a source of energy on the flow conditions. A condensation model therefore is implemented by introducing user defined functions in STAR-CCM+ ${ }^{\circledR}$, as will be explained in section 3. Vyskocil et al. 27] used a similar approach for calculating volume condensation.

There are different approaches to verify CFD simulation results. The physical problem which is faced here consists in the condensation due to the mixing of two gases at different temperatures and specific humidities but at a constant pressure. Mixing process is isenthalpic if both components are considered [33, 34]. If the conditions of the mixed gas results to be supersaturated, water may condensate isenthalpically until it reaches $100 \%$ of relative humidity. An example of how this process is produced is shown in the diagram of Fig. 1. A weighting of mass flow rates is used to calculate the enthalpy (Eq. 1) and the specific humidity (Eq. 2) of the mixed flow. Then, using Eq. (4), the temperature of the mixed flow are obtained.

The analytical solutions used to compare and verify the proposed model in this work correspond to an energy and mass balance system of Eqs. de- 


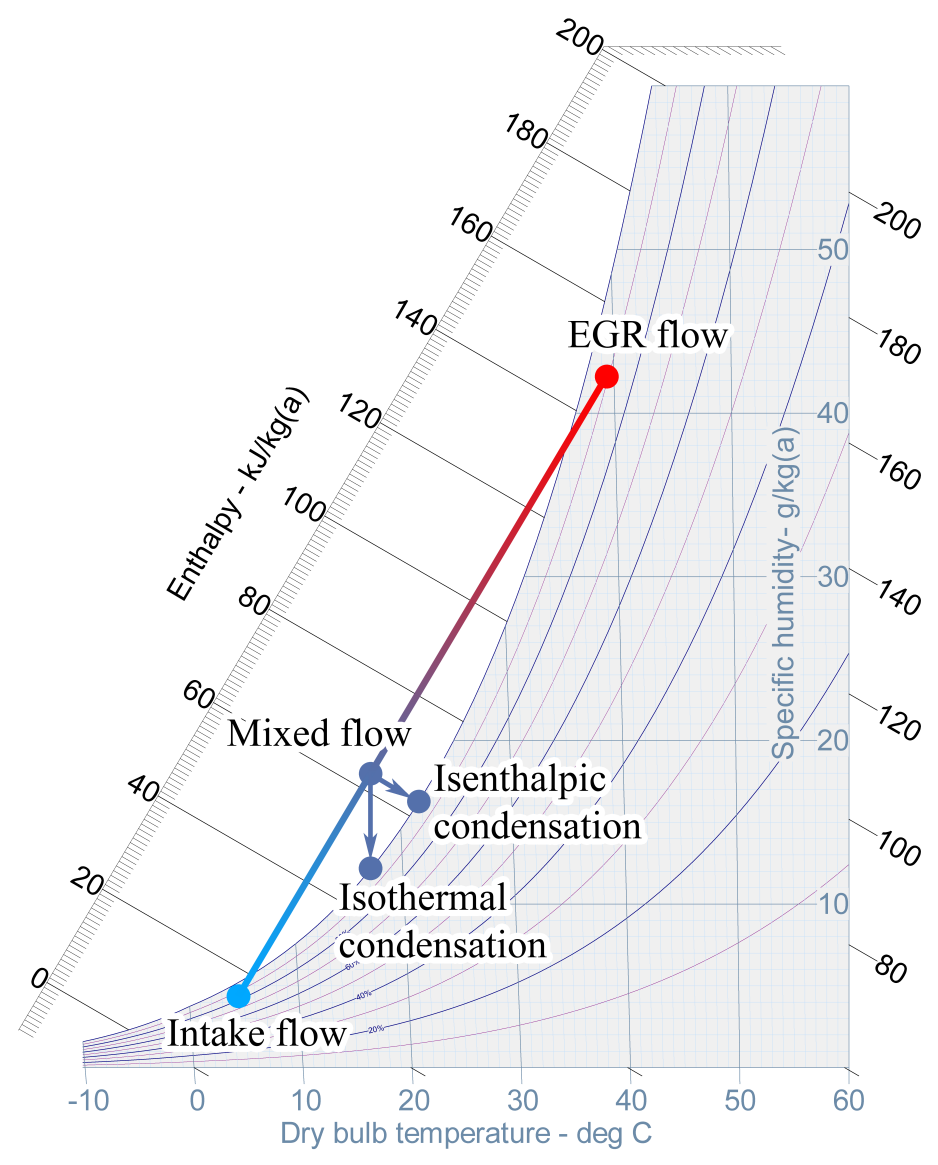

Figure 1: Psychrometric diagram with Isothermal and isenthalpic condensation processes produced when the hot wet flow of the EGR is mixed with the cold dry gas of the intake.

veloped by Serrano et al. [20]. As can be found in the referred work, the conservation equations are solved analytically with an iterative resolution method, to get the final state of a perfect mixing of two gases at different conditions, assuming an isenthalpic evolution. As any 0D balance, the computational effort to get the analytical solution is low but local effects are not considered. Therefore, for the CFD verification, a simple geometry is designed so the condensation model is the only responsible of the process, excluding local effects caused by the mixing process. For this purpose, a premixed option is chosen, thus with a simple straight duct the restrictions are solved. 
The inlet conditions of this single inlet duct are calculated in 3D-CFD codes coupling both flows. Mass flow and mass fractions (the specific humidity) are directly obtained. Nevertheless, for the temperature, a similar process used for calculating the initial mixing point in the diagram method shown in Fig. 1 is used. The enthalpy of the initial mixing is calculated with the mass flow and the enthalpy of each inlet (Eq.1). The temperature is obtained knowing the enthalpy and the specific humidity of the mix [35] (Eq. 4).

$$
\begin{gathered}
h_{m i x}=\frac{h_{i n} \frac{\dot{m}_{i n}}{\frac{w_{i n}}{1000}+1}+h_{E G R} \frac{\dot{m}_{E G R}}{\frac{w_{E G R}}{1000}+1}}{\frac{\dot{m}_{i n}}{\frac{w_{i n}}{1000}+1}+\frac{\dot{m}_{E G R}}{\frac{w_{E G R}}{1000}+1}} \\
w_{m i x}=\frac{w_{i n} \frac{\dot{m}_{i n}}{\frac{w_{i n}}{1000}+1}+w_{E G R} \frac{\dot{m}_{E G R}}{\frac{\dot{w}_{E G R}}{1000}+1}}{\frac{\dot{m}_{\text {in }}}{\frac{w_{i n}}{1000}+1}+\frac{\dot{m}_{E G R}}{\frac{w_{E G R}}{1000}+1}} \\
h=(T-273.15) c_{p_{a i r}}+h_{v a p, s a t} \frac{w}{1000} \\
h=(T-273.15) \frac{w}{c_{p_{a i r}}+(1.76 T+2502.9)} \frac{w}{1000}
\end{gathered}
$$

Finally, the outcomes of the different methods (0D \& 3D) are the temperature and the condensation rate of water in function of the dry air mass flow rate, verifying the flow is at saturated conditions.

\section{Description of proposed condensation model in STAR-CCM+ ${ }^{\circledR}$}

Once the objectives and limitations of the model are known, the hypothesis and simplifications that have been established for this work can be introduced.

- Instantaneous condensation: Relatively low velocities $(\mathrm{M}<0.2)$ control the mixing phenomena in a LR-EGR T-joint, causing the condensation to be practically instantaneous in time and space. The limit will be imposed by the time step and the size of the cell respectively. 
- Liquid water phase is not modeled: The modeling of the water phase exceeds the objectives of this work, which is intended to create a condensation model that predicts the quantity of water generated due to the mixing of two flows at different conditions. In order to obtain this amount, the impact of the condensation calculation in the numerical model should be as low as possible, while the incorporation of an extra phase component in the simulation (with the relative Lagrangian approach) would lead the calculation effort to increase substantially. Nevertheless, as will be explained below, a passive scalar is used to track the condensed water since it does not have much impact in the computational effort required. This simplification implies some small unbalances in the conservation equations, detailed as follows:

- Continuity: Condensed water is taken into account by the passive scalar. However, the mass conservation in the calculated species is not met. The influence of this simplification should be low since condensed water represents less than $0.5 \%$ of the mass flow and hence, it can be neglected.

- Momentum: Following a similar argumentation, the momentum of the liquid water that disappears represents again less than $0.5 \%$ of the total momentum, which has insignificant impact in the solution of the simulation.

- Energy: This term is related to the enthalpy of the vapor that is disappearing, which in this case is below $1 \%$ due to the specific heat capacity of the vapor being twice the specific heat of the dry air. Nevertheless, the energy source term introduced in Eq. (11) takes into account this issue, producing at the end an isenthalpic process.

- Evaporation is not modeled: Potentially, some of the condensed water might be eventually evaporated if water droplets are in contact with sub-saturated flow. However, as will be shown below in Section 5 , once the condensation has occurred the flow remains very close to saturation conditions, which means that the evaporation rate would be minimal, if not zero [36, 37]. Modeling evaporation is challenging since it is not an instantaneous process, its characteristic time depending on the droplet size and other parameters that are not considered to avoid a Lagrangian approach and its subsequent increase of computational effort. In any 
case, this simplification produces a worst-case scenario concerning the condensation rate, keeping the prediction on the safety side.

- Isenthalpic condensation (Fig. 1): During a condensation process, since it is an adiabatic evolution, the enthalpy of the gas is kept constant [33, 34].

- Adiabatic walls: The objective is to predict bulk flow condensation, not condensation on the walls. Enabling heat transfer through the walls would cause water condensation on the walls, requiring a thin film condensation model. Moreover, the verification of the model would not be possible with an energy balance since, in that case, the energy would not be conserved.

The actual condensation phenomenon is not going to be calculated due to the high complexity and computational cost. Instead, its effect on the mass and energy transport equations is going to be modeled taking into account the hypothesis and simplifications exposed above. Transport equations in discrete form for segregated flow simulations can be obtained considering the appropriate terms of Table 1 in the Eq. (5). STAR-CCM+ ${ }^{\circledR}$ [31] allows arbitrary editing the source terms of the transport equations and this is going to be used to model the effect of the condensation. The relationship between the source terms of each equation will define the type of thermodynamic process that the condensation will follow.

$$
\frac{\partial(\rho \varphi)}{\partial t}+\nabla(\rho \varphi \vec{u})=\nabla\left(\rho \Gamma_{\varphi} \nabla(\varphi)\right)+S_{\varphi}
$$

\begin{tabular}{c|c|c|c} 
Equation & $\boldsymbol{\varphi}$ & $\boldsymbol{\Gamma}_{\boldsymbol{\varphi}}$ & $\boldsymbol{S}_{\boldsymbol{\varphi}}$ \\
\hline Mass & 1 & - & $S_{\text {vap }}$ \\
Species & $Y$ & $D$ & $S_{\text {vap }}$ \\
Momentum & $u_{i}$ & $\nu$ & $-\partial p / \partial x_{i}+f_{m}+f_{v}+S_{\text {mom. }}$ \\
Energy & $h$ & $\alpha$ & $-D p / D t+f_{t}+f_{v}+S_{\text {ener. }}$
\end{tabular}

Table 1: Transport equations

The first parameter of the condensation that is considered is the relative humidity $(\mathrm{RH})$, which is introduced in order to identify in which cells the condensation should appear, and is defined as the ratio between the partial pressure of the vapor and the saturation pressure of the dry air (Eq. 6). The 
partial pressure of the vapor is calculated by using the Dalton's law (Eq. 7) and the saturation pressure is obtained adjusting the Antoine equation coefficients with the data tables from Stull [38] valid for a temperature range between 255.9 and $373 \mathrm{~K}$ (Eq. 8) and thus suitable for the application of the current work. The enthalpy of the humid flow is defined in Eq. (4).

$$
\begin{gathered}
\mathrm{RH}=100 \frac{p_{\text {vap }}}{p_{\text {sat }}} \\
p_{\text {vap }}=\frac{p}{1+1000 \frac{\mathrm{MW}_{\mathrm{H}_{2} \mathrm{O}}}{w \cdot \mathrm{MW}_{\text {air }}}} \\
p_{\text {sat }}=10^{4.6543-\frac{1435.26}{T-64.848}}
\end{gathered}
$$

Relative humidities greater than $100 \%$ will trigger condensation occurrence. In Fig. 2 it is depicted a psychrometric diagram in function of the specific humidity, the dry bulb temperature, the relative humidity and the enthalpy. The starting point of the process (1) is placed in the saturated zone, with a relative humidity higher than $100 \%$. If the process of condensation is produced isothermally as in Defogging model of STAR-CCM+ ${ }^{\circledR}$ [31], the final point will be at the intersection of a vertical line from the starting point and the $100 \%$ of relative humidity curve (3). On the other side, if the process is produced isenthalpicly, the final desired point will be at the intersection of an isoenthalpic line with the $100 \%$ relative humidity curve. The value of temperature and specific humidity of this latter point are unknown. Eq. (6) indicates that for saturated conditions, vapor and saturation pressure are equivalent (Eq. 6). With Eqs. (7) and (8) and in addition with the enthalpy Eq. (4), it is formed a system with two equations and two variables.

As the equation system is implicit, the solution cannot be calculated directly. Therefore, a numerical approach has to be established taking into account the limitations of the CFD software and the computational cost. There are two main aspects that must be carefully taken into account. In first place, the enthalpy ought to remain constant. For achieving this, heat may be released as the vapor condensates into water. If this restriction is locally accomplished, the enthalpy will be kept constant globally. In second place, the condensation is imposed to occur instantaneously, which in terms of CFD implies a complete condensation from the initial oversaturated state of a cell to saturated conditions in a single iteration. The size of the cell is then responsible for the local dimensions where the condensation takes place. 


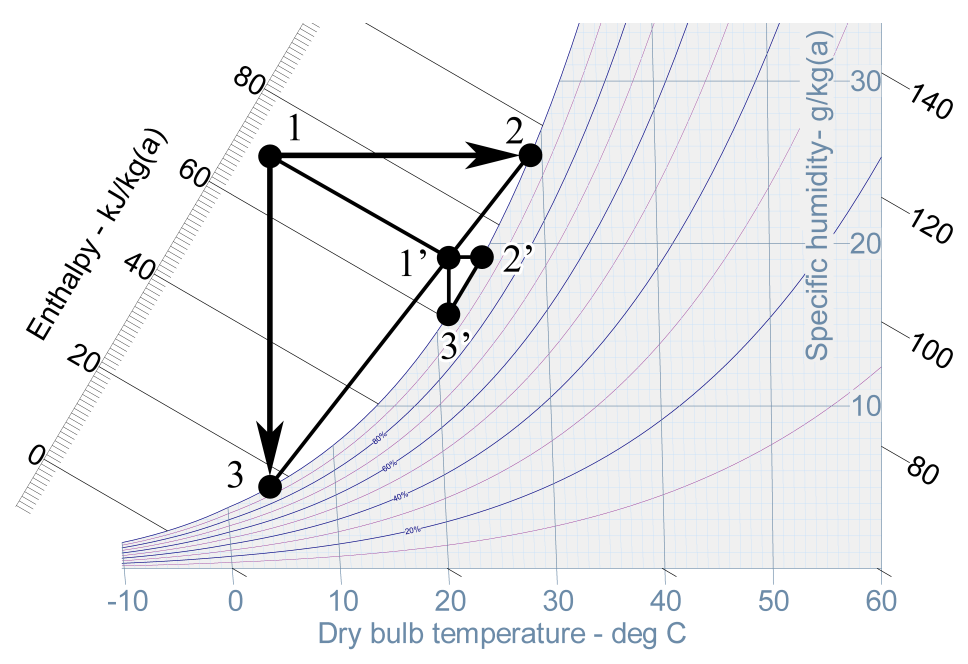

Figure 2: Iterative process of the numerical condensation model in a psychrometric diagram

That means a smaller condensation region for finer meshes. For the sake of accuracy, the size of the cells should be much smaller in comparison with the geometry, so that the influence of this parameter in the global condensation region is negligible.

The numerical model is set up to be iterative, being the number of iterations discussed later on. Fig. 2 will be used to describe the calculation process. From the oversaturated starting point (1) the temperature and the specific humidity are known and thus its enthalpy can be calculated. Points (2) and (3) are obtained moving point (1) at iso-specific humidity and isothermally respectively. The temperature of point (2) and the specific humidity of point (3) can be obtained imposing saturated conditions at Eqs. 7 and 8 . Next, enthalpies of points (2) and (3) are calculated and the specific humidity of point (1') is obtained by interpolating the enthalpies, according to Eq. 9.

$$
w_{1^{\prime}}=\frac{w_{2}-w_{3}}{h_{2}-h_{3}}\left(h_{1}-h_{3}\right)+w_{3}
$$

Finally, the temperature of point (1') is calculated with the enthalpy equation (4). Taking point ( $\left.1^{\prime}\right)$ as the new starting point, the process can be repeated as many times as desired to increase accuracy. When the last iteration is performed, the specific humidity of the last interpolated point 
$\left(w_{f}\right)$ is used to calculate the vapor mass source term shown in Eq. (10).

$$
S_{\text {vap }}=\frac{\rho Y_{\text {air }}\left(w_{f}-w_{1}\right)}{\Delta \mathrm{t}}
$$

The mass source term dimensions required by the 3D-CFD code are $M L^{-3} T^{-1}$. Theoretically, the correct form of calculating this term would be the product of specific humidity times the mass flow rate through the cell and divided by the volume of the cell. This is not possible to be done because calculating the mass flow rate of the cell is not straight forward. One possibility could be taking into account each face of a given cell and calculating the net incoming flow. The sum of the flows of all faces of that given cell would be the mass flow, however, it is not possible with the current version of STAR-CCM $+{ }^{\circledR}$. Instead, density and a characteristic velocity of a cell are used, obtaining a valid approximation of the source term. The denominator term of Eq. 10 is associated to the characteristic time in which the vapor mass source is being added to the flow or, in other words, the residence time of a particle in a given cell. This parameter can be calculated dividing the equivalent diameter of the cell (supposing it is a sphere) by the velocity of the flow in that cell. The energy source term is calculated simply considering the product of the species term and the latent heat of condensation of water (Eq. 11) and subtracting the sensible heat of the condensed vapor.

$$
S_{\text {ener. }}=-S_{\text {vap }}\left(L-c_{p_{\text {vap }}} T\right)
$$

Finally, for the momentum conservation, the corresponding value for the condensed vapor has been removed. In Eq. 12 this term is written. The momentum is the product of the mass times the velocity vector. The mass term is the source term of mass calculated in Eq. 10.

$$
S_{\text {mom. }}=S_{\text {vap }} \vec{u}
$$

Strictly, the mass conservation of the fluid volume is not being maintained since vapor mass is disappearing and a water liquid phase is not being taken into account. The justification of this simplification resides in the ratio between the condensed mass and the total inlet mass, which is below $0.5 \%$ (see Table 4) and thus introduces little error to the conservation equations. Nevertheless, in order to trace the condensates, a passive scalar transport equation is introduced which considers the condensed water. The functioning simply consists in a scalar value that is transported by the flow and increases as the 
condensation takes place, with diffusion and convection driven by a Schmidt number of 0.9 [39]. The condensation rate of the simulation is calculated computing the flow rate of passive scalar across the outlet surface.

To conclude this section, a study of the influence of the number of iterations of the numerical model (Fig. 2) is performed to quantify the impact of this parameter in accuracy of the results and the computational cost. Simulations of the $15 \%$ of EGR rate case from table 3 were performed with one, two and three iteration cycles. Results of condensation rates showed negligible differences $(<1 \%)$ among all the simulations. The explanation resides in the exaggeration of the starting over-saturated point in the phychrometric diagram shown in Fig. 2. In fact, due to the resolution of the mesh and the solvers, the iteration is produced naturally in consecutive cells as the flow passes through. However, the impact on the computational cost is indeed very high. Respect to a reference case without condensation with a normalized iteration time of $100 \%$, for 1, 2 and 3 iterations of the numerical model, the computational time increased to 120, 135 and $250 \%$ respectively, as can be seen in Table 2, For the verification of the model, a single sub-iteration is set and will be justified in Section 4.2 .

\begin{tabular}{|l|c|c|c|c|}
\hline Sub-iterations [-] & 0 & 1 & 2 & 3 \\
\hline Computational time [\%] & 100 & 120 & 135 & 250 \\
\hline
\end{tabular}

Table 2: Normalized computational time for different sub-iterations

\section{Verification}

Since a new model has been developed and implemented, a verification process must be done in order to check that the equations are behaving as intended [40, 41, 42. This process is addressed to detect implementation errors and to quantify the errors due to discretization, round-off and iterative convergence.

\subsection{Numerical setup}

In this section, the configuration of the simulation case is discussed, from choosing the solver to defining the boundary conditions.

Concerning the solver, a segregated model with multi component ideal gas is used and the widely-used RANS k- $\epsilon$ turbulence model [43] is imposed 
to close the flow equations. A time step of $1 \cdot 10^{-4}$ is used to capture oscillations with characteristic lengths below the duct diameter. Gravitational effects are neglected since the Froude number, calculated from gravity and characteristics velocity and length, is around 25, much greater than 1, implying greater influence of inertial forces compared with gravitational ones. Conventional boundary conditions are used i.e., mass flow and temperature are imposed for the inlet and a constant static pressure is set for the outlet.

Regarding the CFD configuration of the mesh, polyhedral cells have been used, with an average cell length of $1.8 \mathrm{~mm}$, resulting in about 400k cells. In addition, eight prism layers are imposed at the walls to increase boundary layer resolution. An independence mesh study has been performed with two additional meshes, presenting respectively one fourth and four times the number of cells compared with the reference one. Discrepancies below $1 \%$ in global variables including condensation rate were found in the finer mesh, whereas for the coarser one discrepancies were above 5\%. Therefore the reference mesh with 400k cells was selected.

Operating parameters of the simulations are not arbitrary but are within the range of a LR-EGR engine working in very cold climates since such low ambient temperatures suppose a worst case scenario in terms of condensation.

Table 3 summarizes the parameters that were used to define the boundary conditions of the different simulations. Five working points are defined, covering a wide range of EGR rate thus allowing a comprehensive verification of the model.

\begin{tabular}{l|r}
\hline Ambient temperature $\left[{ }^{\circ} \mathbf{C}\right]$ & -15 \\
\hline Ambient $\mathbf{R H}[\%]$ & 100 \\
\hline Ambient specific humidity [g/kg dry air] & 1.62 \\
\hline LR-EGR rate [\%] & $5,10,15,20,25$ \\
\hline LR-EGR cooler outlet temperature $\left[{ }^{\circ} \mathbf{C}\right]$ & 55 \\
\hline LR-EGR specific humidity $[\mathrm{g} / \mathrm{kg}$ dry air] & 50 \\
\hline
\end{tabular}

Table 3: Operating conditions

\subsection{Results and discussion}

Table 4 shows the results of outlet temperature and condensation rate provided by the 3D-CFD simulations with the developed condensation model at the operating conditions defined by table 3 . Table 4 includes the 3D-CFD 
prediction in terms of absolute values and relative differences when compared to the $0 \mathrm{D}$ balance.

\begin{tabular}{|l|c|c|c|c|}
\hline Model & $T_{\text {out }}[\mathrm{K}]$ & $\frac{\dot{m}_{\mathrm{H}_{2} \mathrm{O}}}{\dot{m}_{\text {air }}}[-]$ & $\Delta \mathrm{T}[K]$ & $\epsilon \frac{\dot{m}_{\mathrm{H}_{2} \mathrm{O}}}{\dot{m}_{\text {air }}}[\%]$ \\
\hline 5\% EGR rate \\
\hline 0D balance & 265.20 & $1.46 \cdot 10^{-3}$ & \\
\hline 3D-CFD & 265.27 & $1.46 \cdot 10^{-3}$ & 0.07 & -0.46 \\
\hline \multicolumn{6}{|c|}{$\mathbf{1 0 \%}$ EGR rate } \\
\hline 0D balance & 271.38 & $2.58 \cdot 10^{-3}$ & \\
\hline 3D-CFD & 271.46 & $2.56 \cdot 10^{-3}$ & 0.08 & -0.45 \\
\hline \multicolumn{6}{|c|}{$\mathbf{1 5 \%}$ EGR rate } \\
\hline 0D balance & 276.72 & $3.35 \cdot 10^{-3}$ & -0.20 \\
\hline 3D-CFD & 276.78 & $3.34 \cdot 10^{-3}$ & 0.05 & \\
\hline \multicolumn{7}{|c|}{$\mathbf{2 0 \%}$ EGR rate } \\
\hline 0D balance & 281.34 & $3.82 \cdot 10^{-3}$ & \\
\hline 3D-CFD & 281.36 & $3.83 \cdot 10^{-3}$ & 0.02 & 0.19 \\
\hline \multicolumn{7}{|c|}{$\mathbf{2 5 \%}$ EGR rate } \\
\hline 0D balance & 285.34 & $4.05 \cdot 10^{-3}$ & \\
\hline 3D-CFD & 285.34 & $4.07 \cdot 10^{-3}$ & -0.01 & 0.69 \\
\hline
\end{tabular}

Table 4: Result summary and comparison

Comparisons are performed using the perfect mixing 0D balance equations developed by Serrano et al. [20] as the reference. Regarding 3D simulation, errors below $1 \%$ are found for water condensation and temperature for all the range of EGR rate. High accuracy is reasonable, since the same equations are used for both 3D-CFD and 0D balance. Minor discrepancies are due to numerical error and local effects. Since condensation is triggered by over-saturated conditions, the 3D simulations will always end the process by the side of non-saturated conditions. Normally, final relative humidities are around $99.75 \%$, what would imply slightly more condensation and increased temperature if the process is being perfectly isenthalpic.

In Fig. 3 it is depicted the condensation rate evolution along the axis cross-sections for the 15\% EGR rate case of Table 3. Due to the premixed state of the inlet flow the condensation process takes place within the very first part of the duct. Afterwards, equilibrium conditions are reached and kept constant until the outlet of the duct. Comparing this evolution with the solution of the 0D perfect mixing balance, for the same inlet conditions, 
it can be seen the perfect agreement of the 3D simulation.

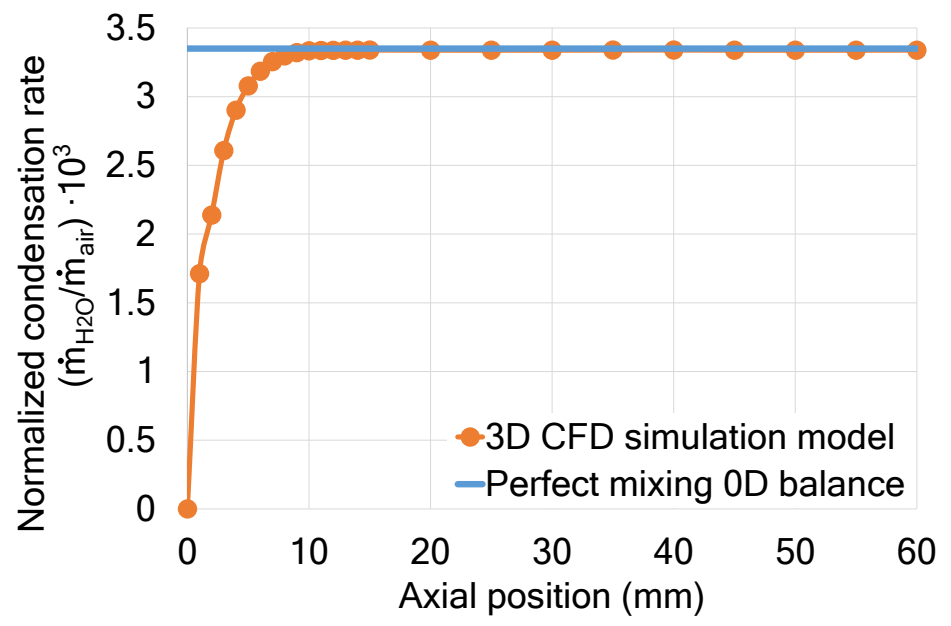

Figure 3: Condensation rate evolution during the duct inlet.

Fig. 4 corresponds to a detailed section of the specific humidity scalar field in the inlet duct. The mesh has been superimposed allowing to notice the specific number of cells the condensation process needs to reach saturated conditions.

The premixed conditions of the inlet flow set a worst case scenario where all the condensation process is done almost instantaneously, i.e. in a short length.

Taking into account the base size of the cells and a mean number of 4 cells that are required to reach the saturation, the length required for a total condensation is about $7 \mathrm{~mm}$. Mainly due to the single sub-iteration and the approximation of the mass source term, condensation is not being instantaneous (not produced in a single cell). In order to reduce the length of the condensation interface there are two possible approaches. On one hand, the number of sub-iterations of the condensation model could be increased, implying a rise in the computational effort as aforementioned. On the other hand, the mesh density could be increased so that not only the condensation length decreases but also the discretization error is reduced in the rest of the transport equations. Even though the latter approach also implies a rise in the computational effort, it is preferable against the first option. 


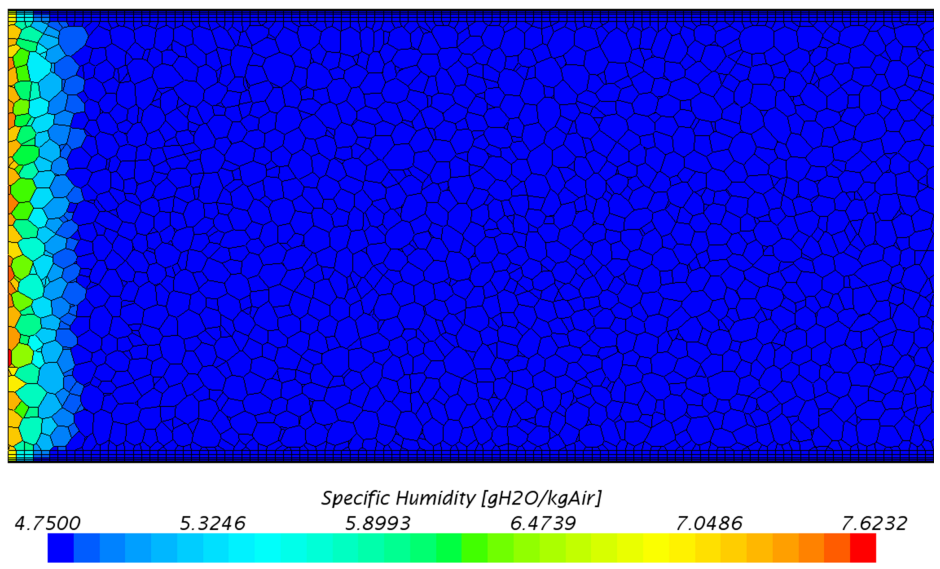

Figure 4: Scalar of specific humidity.

\section{Practical example}

In this section, an example of a practical use of the model developed in this work is showed. This example is not intended to provide a proper validation. In fact, comparisons with experimental data are not going to be made. That study is proposed as a future work. The geometry consists in a T-joint, composed by an intake duct and a secondary duct that simulates the discharge of LR-EGR (Fig. 5). Inside both ducts there are flaps that control mass flow rates. Duct lengths are enough to assure developed conditions. The post-processing plane used throughout this section is included in Fig. 5.

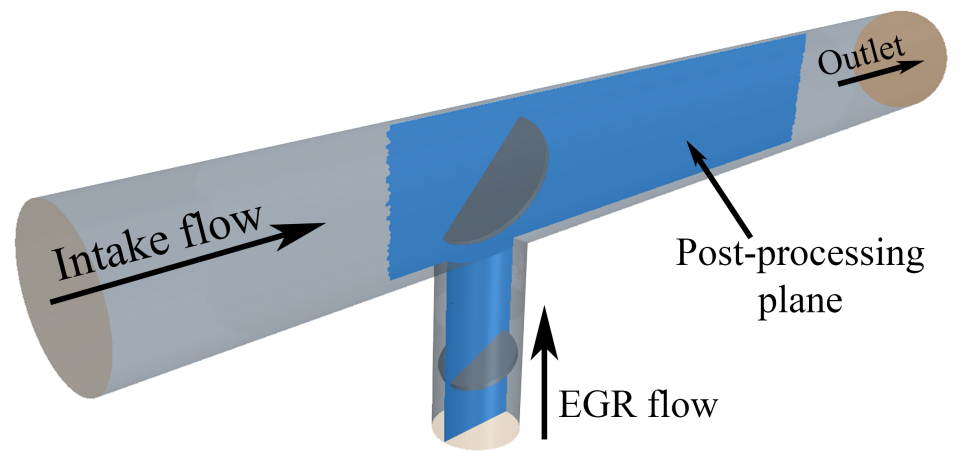

Figure 5: Geometry.

Regarding the setup, configuration described in Section 4.1 is used. Bound- 
ary conditions for the intake and the EGR duct correspond to the $15 \%$ EGR rate case from table 3 ,

The evolution of the relative humidity can be appreciated in Fig. 6, where the convergence to saturation condition can be noticed. A line integral convolution [44] of the velocity vectors is blended with relative humidity contours and velocity vectors are overimposed. The blue solid line highlights the zone of constant relative humidity of $95 \%$, showing that once both streams start mixing and eventually condensing, the mixed gas remains very close to saturation conditions, preventing a potential re-evaporation of the condensed water to occur.

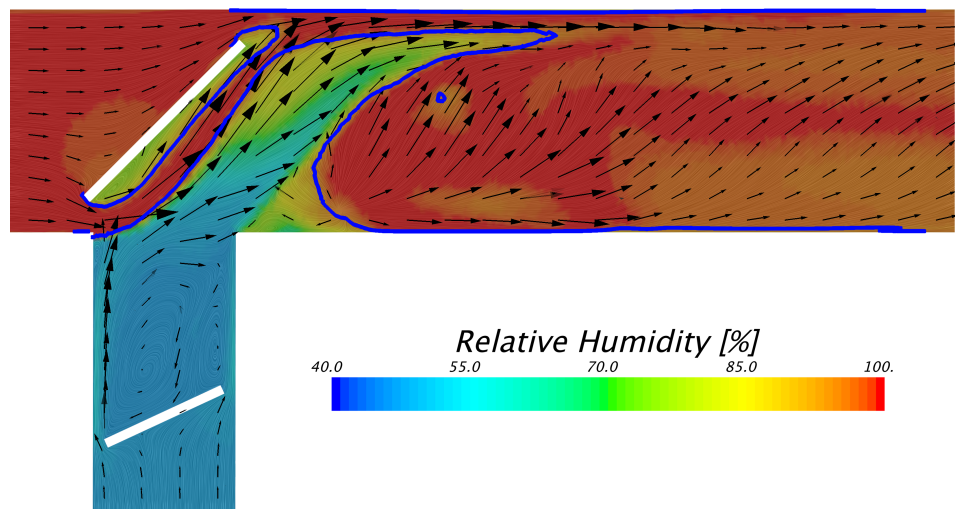

Figure 6: Linear integral convolution of velocity colored by relative humidity and velocity vectors in a LR-EGR junction with a $15 \%$ of EGR rate. The blue solid line indicates a $95 \%$ of relative humidity.

Finally, in Fig. 7 it is shown a scene of the passive scalar used in the simulations to emulate the water transport. The mixing process of both flows causes a high condensation rate, implying water droplets generation and potential damage of the compressor wheel.

As can be observed in Figs. 67and 7, the hot and humid flow coming from the LR-EGR discharges into the intake duct, where it gets surrounded by the cold ambient flow, overpassing saturation conditions and thus generating water condensation. The water passive scalar is diluted within the flow due to convection and diffusion. As the flow stream gets far from the intake flap, water mass fraction becomes more homogeneous. 


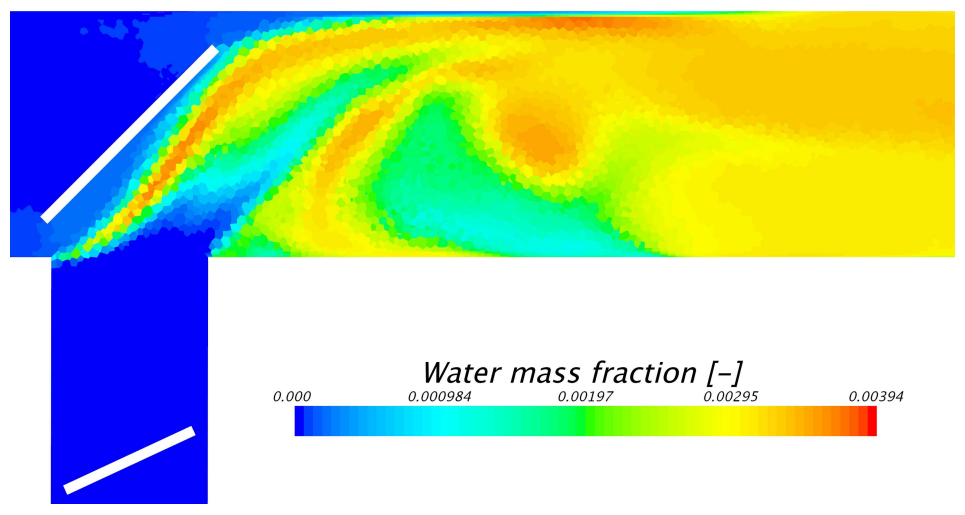

Figure 7: Scalar of passive scalar for the LR-EGR case of $15 \%$

\section{Conclusions}

A collection of suitable source terms to model water condensation in humid air stream have been developed and implemented within the code of a commercial 3D CFD software. The capabilities and limitations of the model have been exposed, and fulfill the requirements and objectives regarding computational cost and accuracy in the condensation prediction in LR-EGR systems. A previously validated 0D perfect mixing system of balance equations has been used in order to compare the global results of the simulation with analytical solutions for a wide range of boundary conditions in terms of specific humidity and temperatures. With a practical example, the applicability of the model is shown, highlighting which parameters may be used to evaluate local effects in an actual simulation.

Before the model is able to be used for the intended application, a validation of the condensation model in real flow mixing conditions is required, comparing with experimental data. In addition, a study of the sensitivity of the model to the numerical setup is also proposed, observing how the variation of parameters such as mesh, time step, turbulence model, etc affects the solution accuracy.

\section{Acknowledgements}

The authors gratefully acknowledge Joaquín de la Morena and Alberto Racca from GM Global Propulsion Systems-Torino Srl for their support and feedback in the application of the model. The authors also would like to thank 
Mr. Rubén Ibáñez for his worthy assistance to implement the condensation model in STAR-CCM $+{ }^{\circledR}$.

Daniel Tarí is partially supported through contract FPI-S2-2015-1095 of Programa de Apoyo para la Investigación y Desarrollo (PAID) of Universitat Politècnica de València.

\begin{tabular}{lll}
\multicolumn{2}{l}{ List of Symbols } & \\
$c_{p}$ & isobaric specific heat capacity & $\mathrm{J} \cdot \mathrm{kg}^{-1} \cdot \mathrm{K}^{-1}$ \\
$D$ & diffusion coefficient & $\mathrm{m}^{2} \cdot \mathrm{s}^{-1}$ \\
$f$ & additonal terms & \\
$h$ & enthalpy & $\mathrm{J} \cdot \mathrm{kg}^{-1} \cdot \mathrm{K}^{-1}$ \\
$L$ & latent heat & $\mathrm{J} \cdot \mathrm{kg}^{-1}$ \\
$M W$ & molecular weight & $\mathrm{kg} \cdot \mathrm{mol}^{-1}$ \\
$\dot{m}$ & mass flow rate & $\mathrm{kg} \cdot \mathrm{s}^{-1}$ \\
$p$ & pressure & $\mathrm{bar}$ \\
$R H$ & relative humidity & $\%$ \\
$S$ & source term & \\
$t$ & time & $\mathrm{s}$ \\
$T$ & temperature & $\mathrm{K}$ \\
$\vec{u}$ & velocity & $\mathrm{m} \cdot \mathrm{s}^{-1}$ \\
$w$ & specific humidity & $\mathrm{g}_{\mathrm{H}_{2} \mathrm{O} \cdot \mathrm{kg}}$ \\
$x$ & coordinate in dominant direction & $\mathrm{m}$ \\
$Y$ & mass fraction & \\
$\alpha$ & thermal diffusivity & $\mathrm{m}^{2} \cdot \mathrm{s}^{-1}$ \\
$\Delta t$ & characteristic time & $\mathrm{s}$ \\
$\epsilon$ & relative difference & $\%$ \\
$\nu$ & kinematic viscosity & $\mathrm{m}^{2} \cdot \mathrm{s}^{-1}$ \\
$\varphi$ & generic variable & \\
$\rho$ & density & $\mathrm{kg} \cdot \mathrm{m}^{-3}$ \\
& &
\end{tabular}

\section{References}

[1] F. Posada, A. Bandivadekar, J. German, Estimated cost of emission control technologies for light-duty vehicles part 1-gasoline, Tech. rep., SAE Technical Paper 2013-01-0534 (2013). doi:10.4271/2013-01-0534.

[2] F. Posada, A. Bandivadekar, J. German, Estimated cost of emission 


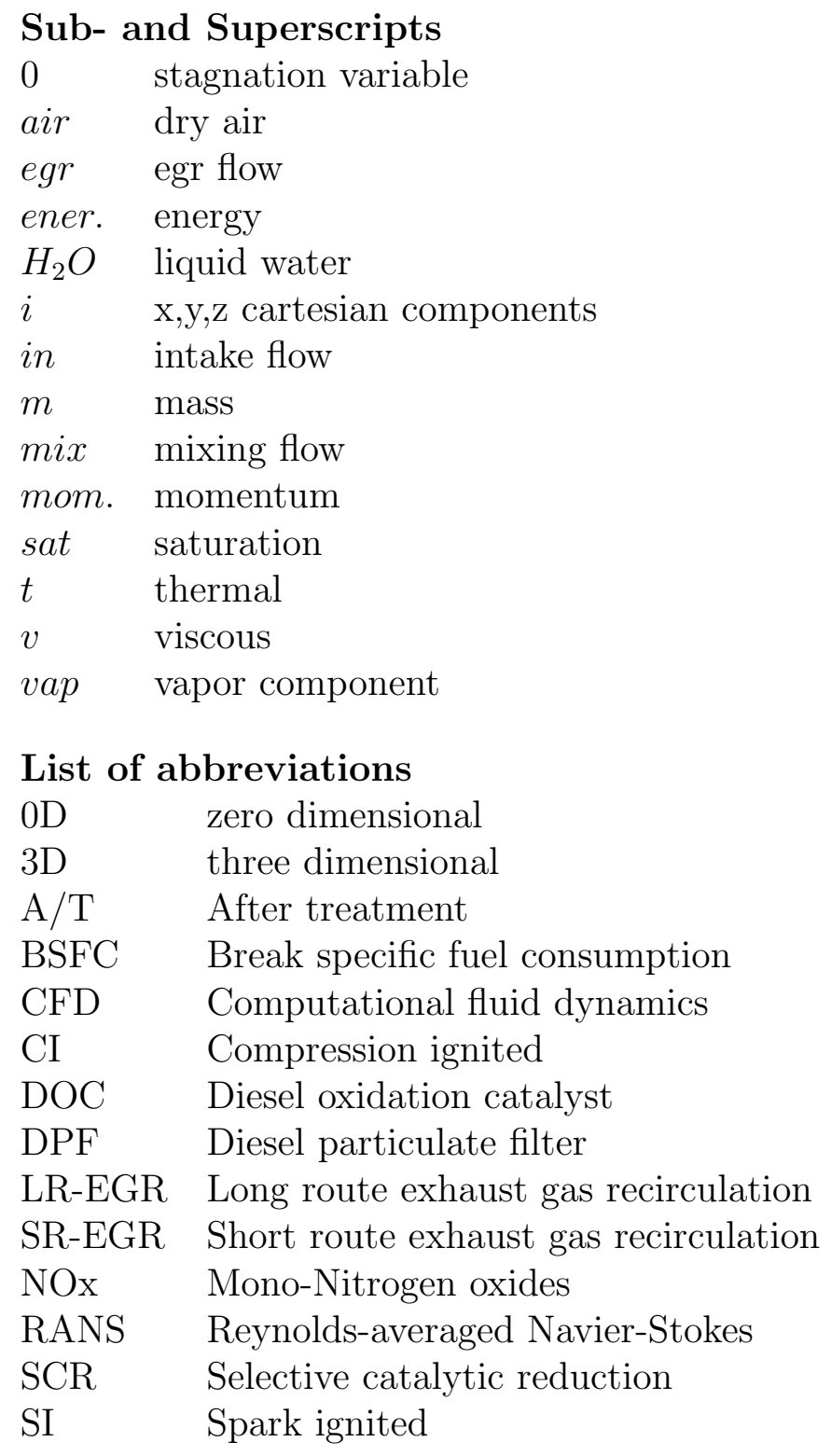

control technologies for light-duty vehicles part 2-diesel, Tech. rep., SAE Technical Paper 2013-01-0539 (2013). doi:10.4271/2013-01-0539.

[3] R. Mobasheri, Z. Peng, CFD investigation into diesel fuel injection schemes with aid of Homogeneity Factor, Computers \& Fluids 77 (Supplement C) (2013) 12 - 23. doi:10.1016/j.compfluid.2013.02.013. 
[4] J. M. Luján, H. Climent, V. Dolz, A. Moratal, J. Borges-Alejo, Z. Soukeur, Potential of exhaust heat recovery for intake charge heating in a diesel engine transient operation at cold conditions, Applied Thermal Engineering 105 (2016) 501-508. doi:10.1016/j. applthermaleng.2016.03.028.

[5] T. V. Johnson, Review of vehicular emissions trends, SAE Int. J. Engines 8 1152-1167. doi:10.4271/2015-01-0993.

[6] C. Guardiola, B. Pla, P. Piqueras, J. Mora, D. Lefebvre, Model-based passive and active diagnostics strategies for diesel oxidation catalysts, Applied Thermal Engineering 110 (2017) 962-971. doi:10.1016/j. applthermaleng.2016.08.207.

[7] A. Cairns, N. Fraser, H. Blaxill, Pre versus post compressor supply of cooled EGR for full load fuel economy in turbocharged gasoline engines, Tech. rep., SAE Technical Paper 2008-01-0425 (2008). doi:10.4271/ 2008-01-0425.

[8] J. M. Luján, H. Climent, R. Novella, M. E. Rivas-Perea, Influence of a low pressure EGR loop on a gasoline turbocharged direct injection engine, Applied Thermal Engineering 89 (2015) 432-443. doi:10.1016/ j.applthermaleng.2015.06.039.

[9] J. M. Desantes, J. M. Luján, B. Pla, J. A. Soler, On the combination of high-pressure and low-pressure exhaust gas recirculation loops for improved fuel economy and reduced emissions in high-speed directinjection engines, International Journal of Engine Research 14 (1) (2013) 3-11. doi:10.1177/1468087412437623.

[10] N. Ladommatos, S. Abdelhalim, H. Zhao, The effects of exhaust gas recirculation on diesel combustion and emissions, International Journal of Engine Research 1 (1) (2000) 107-126. doi:10.1243/ 1468087001545290 .

[11] J. Luján, B. Pla, S. Moroz, G. Bourgoin, Effect of low pressure EGR on gas exchange processes and turbocharging of a HSDI engine, in: Proceedings of the conference on thermo-and fluid-dynamic processes in diesel engines (THIESEL 2008), Valencia, Spain, paper E, Vol. 2, 2008. 
[12] L. Cornolti, A. Onorati, T. Cerri, G. Montenegro, F. Piscaglia, 1D simulation of a turbocharged Diesel engine with comparison of short and long EGR route solutions, Applied Energy 111 (2013) 1-15. doi: 10.1016/j.apenergy.2013.04.016.

[13] J. Galindo, A. Tiseira, R. Navarro, D. Tarí, C. M. Meano, Effect of the inlet geometry on performance, surge margin and noise emission of an automotive turbocharger compressor, Applied Thermal Engineering 110 (2017) 875-882. doi:10.1016/j.applthermaleng.2016.08.099.

[14] J. R. Serrano, X. Margot, A. Tiseira, L. M. García-Cuevas, Optimization of the inlet air line of an automotive turbocharger, International Journal of Engine Research 14 (1) (2013) 92-104. doi:10.1177/ 1468087412449085 .

[15] M. Abarham, T. Chafekar, J. Hoard, D. Styles, D. Assanis, A visualization test setup for investigation of water-deposit interaction in a surrogate rectangular cooler exposed to diesel exhaust flow, SAE Technical Paper 2012-01-0364. doi:10.4271/2012-01-0364.

[16] A. Warey, A. S. Bika, D. Long, S. Balestrino, P. Szymkowicz, Influence of water vapor condensation on exhaust gas recirculation cooler fouling, International Journal of Heat and Mass Transfer 65 (2013) 807-816. doi:10.1016/j.ijheatmasstransfer.2013.06.063

[17] G. Bourgoin, E. Tomas, J. Luján, B. Pla, Acidic Condensation in HP EGR Systems Cooled at Low Temperature Using Diesel and Biodiesel Fuels, SAE Technical Paper 2010-01-1530. doi:10.4271/ 2010-01-1530.

[18] S. Moroz, G. Bourgoin, J. M. Luján, B. Pla, Acidic condensation in low pressure EGR systems using diesel and biodiesel fuels, SAE Int. J. Fuels Lubr 2009-01-2805. doi:10.4271/2009-01-2805.

[19] A. Castorrini, A. Corsini, F. Rispoli, P. Venturini, K. Takizawa, T. E. Tezduyar, Computational analysis of wind-turbine blade rain erosion, Computers \& Fluids 141 (Supplement C) (2016) 175 - 183. doi:10. 1016/j.compfluid.2016.08.013.

[20] J. R. Serrano, P. Piqueras, E. Angiolini, C. Meano, J. De La Morena, On cooler and mixing condensation phenomena in the long-route exhaust 
gas recirculation line, Tech. rep., SAE Technical Paper 2015-24-2521 (2015). doi:10.4271/2015-24-2521.

[21] P. Z. John, T. Koka, S. Dayalan, Water droplet erosion simulation of a turbocharger compressor wheel, in: ASME Turbo Expo 2014: Turbine Technical Conference and Exposition, no. GT2014-26974, American Society of Mechanical Engineers, 2014.

[22] A. Surendran, H. D. Kim, Effects of Wet Compression on the Flow Behavior of a Centrifugal Compressor: A CFD Analysis, in: ASME Turbo Expo 2014: Turbine Technical Conference and Exposition, no. GT2014-25035, American Society of Mechanical Engineers, 2014, p. V02DT42A002. doi:10.1115/GT2014-25035.

[23] S. J. Kim, H. C. No, Turbulent film condensation of high pressure steam in a vertical tube, International Journal of Heat and Mass Transfer 43 (21) (2000) 4031-4042. doi:10.1016/S0017-9310(00)00015-6.

[24] P. Panday, Two-dimensional turbulent film condensation of vapours flowing inside a vertical tube and between parallel plates: a numerical approach, International journal of refrigeration 26 (4) (2003) 492-503. doi:10.1016/S0140-7007(02)00162-7.

[25] J. Liu, H. Aizawa, H. Yoshino, CFD prediction of surface condensation on walls and its experimental validation, Building and Environment 39 (8) (2004) 905-911. doi:10.1016/j.buildenv.2004.01.015.

[26] D.-Y. Shang, L.-C. Zhong, Extensive study on laminar free film condensation from vapor-gas mixture, International Journal of Heat and Mass Transfer 51 (17) (2008) 4300-4314. doi:10.1016/j. ijheatmasstransfer.2008.03.004.

[27] L. Vyskocil, J. Schmid, J. Macek, CFD simulation of air-steam flow with condensation, Nuclear Engineering and Design 279 (2014) 147-157. doi:10.1016/j.nucengdes.2014.02.014.

[28] A. Broatch, J. Galindo, R. Navarro, J. García-Tíscar, Numerical and experimental analysis of automotive turbocharger compressor aeroacoustics at different operating conditions, International Journal of Heat and Fluid Flowdoi:10.1016/j.ijheatfluidflow.2016.04.003. 
[29] C. Moses, G. Stein, On the growth of steam droplets formed in a laval nozzle using both static pressure and light scattering measurements, Journal of Fluids Engineering 100 (3) (1978) 311-322. doi:10.1115/1. 3448672 .

[30] M. Grubel, J. Starzmann, M. Schatz, T. Eberle, D. Vogt, Two-phase flow modeling and measurements in low-pressure turbines-part 1: Numerical validation of wet steam models and turbine modeling, 2014. doi:10. 1115/GT2014-25244.

[31] CD-adapco, STAR-CCM+, release version 9.04.011 Edition (2014). URL http: //www.cd-adapco.com

[32] S. Sen, M. Selokar, D. Nisad, K. Kishore, Design and development of demisting device of a commercial vehicle and its numerical as well as experimental validation, Tech. rep., SAE Technical Paper 2016-01-0217 (2016). doi:10.4271/2016-01-0217.

[33] Psychrometric Chart - Structure and Application, Siemens Building Technologies Group, 2014. URL WWW.siemens.com

[34] D. C. Shallcross, Psychrometric charts for water vapour in natural gas, Journal of Petroleum Science and Engineering 61 (1) (2008) 1-8. doi: $10.1016 / \mathrm{j}$.petrol.2007.10.002.

[35] M. J. Moran, H. N. Shapiro, D. D. Boettner, M. B. Bailey, Fundamentals of engineering thermodynamics, John Wiley \& Sons, 2010.

[36] G. Ferron, S. Soderholm, Estimation of the evaporation or stabilization times of water droplets, Journal of Aerosol Science 18 (6) (1987) 639 642. doi:http://dx.doi.org/10.1016/0021-8502(87)90086-3.

[37] H. Barrow, C. Pope, Droplet evaporation with reference to the effectiveness of water-mist cooling, Applied Energy 84 (4) (2007) $404-412$. doi:https://doi.org/10.1016/j.apenergy.2006.09.007.

[38] D. R. Stull, Vapor pressure of pure substances. organic and inorganic compounds, Industrial \& Engineering Chemistry 39 (4) (1947) 517-540. doi:10.1021/ie50448a022. 
[39] Y. Tominaga, T. Stathopoulos, Turbulent Schmidt numbers for CFD analysis with various types of flowfield, Atmospheric Environment 41 (37) (2007) 8091 - 8099. doi:https://doi.org/10.1016/j. atmosenv.2007.06.054

[40] P. J. Roache, Verification and validation in computational science and engineering, Vol. 895, Hermosa Albuquerque, NM, 1998.

[41] H. K. Versteeg, W. Malalasekera, An introduction to computational fluid dynamics: the finite volume method, 2nd Edition, Pearson Education Limited, 2007.

[42] S. P. Veluri, C. J. Roy, E. A. Luke, Comprehensive code verification techniques for finite volume CFD codes, Computers \& Fluids 70 (Supplement C) (2012) 59 - 72. doi:10.1016/j.compfluid.2012.04.028.

[43] D. C. Wilcox, Reassessment of the scale-determining equation for advanced turbulence models, AIAA journal 26 (11) (1988) 1299-1310. doi:10.2514/3.10041.

[44] B. Cabral, L. C. Leedom, Imaging vector fields using line integral convolution, in: Proceedings of the $20^{\text {th }}$ annual conference on Computer graphics and interactive techniques, ACM, 1993, pp. 263-270. doi:10.1145/166117.166151. 